\title{
Comparative molecular analysis of early and late cancer cachexia-induced muscle wasting in mouse models
}

\author{
RULIN SUN ${ }^{1}$, SANTAO ZHANG $^{1}$, XING LU ${ }^{1}$, WENJUN HU ${ }^{1}$, NING LOU $^{2}$, \\ YAN ZHAO $^{1}$, JIA ZHOU ${ }^{1}$, XIAOPING ZHANG ${ }^{2}$ and HONGMEI YANG ${ }^{1}$ \\ ${ }^{1}$ Department of Pathogenic Biology, School of Basic Medicine, Tonji Medical College, \\ Huazhong University of Science and Technology, Wuhan, Hubei 430030; ${ }^{2}$ Department of Urology, Union Hospital, \\ Tongji Medical College, Huazhong University of Science and Technology, Wuhan, Hubei 430022, P.R. China
}

Received March 2, 2016; Accepted June 14, 2016

DOI: $10.3892 /$ or.2016.5165

\begin{abstract}
Cancer-induced muscle wasting, which commonly occurs in cancer cachexia, is characterized by impaired quality of life and poor patient survival. To identify an appropriate treatment, research on the mechanism underlying muscle wasting is essential. Thus far, studies on muscle wasting using cancer cachectic models have generally focused on early cancer cachexia (ECC), before severe body weight loss occurs. In the present study, we established models of ECC and late cancer cachexia (LCC) and compared different stages of cancer cachexia using two cancer cachectic mouse models induced by colon-26 (C26) adenocarcinoma or Lewis lung carcinoma (LLC). In each model, tumor-bearing (TB) and control (CN) mice were injected with cancer cells and PBS, respectively. The TB and $\mathrm{CN}$ mice, which were euthanized on the 24th day or the 36th day after injection, were defined as the ECC and ECC-CN mice or the LCC and LCC-CN mice. In addition, the tissues were harvested and analyzed. We found that both the ECC and LCC mice developed cancer cachexia. The amounts of muscle loss differed between the ECC and LCC mice. Moreover, the expression of some molecules was altered in the muscles from the LCC mice but not in those from the ECC mice compared with their $\mathrm{CN}$ mice. In conclusion, the molecules with altered expression in the muscles from the ECC and LCC mice were not exactly the same. These findings may provide some clues for therapy which could prevent the muscle wasting in cancer cachexia from progression to the late stage.
\end{abstract}

Correspondence to: Dr Hongmei Yang, Department of Pathogenic Biology, School of Basic Medicine, Tonji Medical College, Huazhong University of Science and Technology, 13 Hangkong Road, Wuhan, Hubei 430030, P.R. China

E-mail: hyang@hust.edu.cn

Dr Xiaoping Zhang, Department of Urology, Union Hospital, Tongji Medical College, Huazhong University of Science and Technology, 1277 Jiefang Avenue, Wuhan, Hubei 430022, P.R. China

E-mail: xzhang@hust.edu.cn

Key words: early cancer cachexia, late cancer cachexia, muscle wasting, PGC1 $\alpha, \mathrm{C} / \mathrm{EBP} \beta$, HDACs

\section{Introduction}

Cachexia has two well-known features: weight loss (mainly due to loss of skeletal muscle and body fat) and inflammation. This syndrome is prevalent in cancer patients, and muscle wasting is the most prominent symptom of cancer cachexia. It is well known that muscle wasting in cancer cachexia is directly related to the poor quality of life of cancer patients and even impacts their survival (1). The current clinical therapy for muscle wasting contributes to the recovery of cancer patients, but the mortality rate of cancer is still rising. Consequently, a novel strategy for the clinical treatment of cancer-induced muscle wasting is urgently required, and research on this subject is highly necessary (2).

To date, for both practical and ethical reasons, studies on muscle wasting have mainly depended on the use of murine models. Among the many available models, the colon-26 adenocarcinoma (C26) and Lewis lung carcinoma (LLC) models are the most commonly used $(3,4)$. Many researchers worldwide have attempted to elucidate the molecular mechanism underlying muscle wasting using the two models (5-16).

Many studies have shown that an intricate regulatory network is involved in muscle wasting (17). Increasing evidence indicates that pro-inflammatory mediators, protein degradation-associated factors, and some other circulating mediators drive this process (18). In addition, the functions of several molecules in this process have been demonstrated, particularly their downstream signaling transduction pathways (17).

Myostatin, which functions specifically as a negative regulator of skeletal muscle growth, is present at a higher level in serum of cancer cachectic mice than in those of normal healthy mice (19-21). Activation of myostatin signaling in muscle tissue has been demonstrated to be critical to enhancing muscle catabolism, which causes muscle wasting in cancer cachexia (22). Myostatin binding to type IIB activin receptor (ActRIIB) on muscle surface induces the recruitment and activation of activin receptor-like kinase 5 (ALK5), and eventually leads to forkhead box O3 (FoxO3a)-dependent transcription to promote muscle protein breakdown via the ubiquitin-proteasome system (23). During the process, myostatin induces a reduction in the phospho-FoxO3a level $(24,25)$. Dephosphorylation 
of FoxO3a leads to its nuclear entry (26). Nuclear FoxO3a activates the atrogin1 promoter (27). Atrogin1 and muscle RING-finger 1 (MuRF1) are two important muscle-specific ubiquitin ligases that are induced in almost all types of muscle wasting (28-30). The ubiquitin proteasome system and autophagy system are two major proteolytic systems involved in skeletal muscle wasting $(31,32)$. Ubiquitin ligases tag myofilament proteins, such as myosin, with ubiquitin groups and target them for degradation (33). Atrogin1, a crucial factor that promotes muscle protein breakdown, is one of the most important downstream molecules of the myostatin signaling pathway (34). Therefore, the myostatin-atrogin1 axis plays a crucial role in the process of muscle wasting. Furthermore, this axis can be regulated by several other molecules.

The activity of FoxO3a is inhibited by an important transcriptional coactivator, peroxisome proliferator-activated receptor gamma coactivator 1 alpha (PGCl $\alpha$ ), which is stimulated by signals that maintain energy and nutrient homeostasis and involved in important metabolic pathways in muscular tissue (35-37). PGCl $\alpha$ is decreased during muscle wasting, and overexpression of PGC1 $\alpha$ inhibits loss of muscle in denervation, hindlimb unloading, sarcopenia and metabolic disease in mice (38-40).

CCAAT/enhancer binding protein beta $(\mathrm{C} / \mathrm{EBP} \beta)$ is an important transcription factor involved in cellular metabolism and inflammation (41). The expression level of C/EBP $\beta$ is increased during muscle wasting under multiple conditions $(42,43)$. Activated p38 $\beta$ mitogen-activated protein kinase (MAPK) interacts with and phosphorylates C/EBP $\beta$, promoting the binding of $\mathrm{C} / \mathrm{EBP} \beta$ to the atrogin 1 promoter in the muscle tissues of cancer cachectic mice $(10,44)$.

Histone deacetylases (HDACs) are the most well known for their roles in the regulation of muscle development and differentiation (45). Subsequent research found that protein deacetylation by HDACs was associated with muscle atrophy in certain conditions (46-48). More recently, class I HDACs have been demonstrated to promote muscle atrophy during nutrient deprivation. Further research has revealed that overexpression of HDAC1 is sufficient to enhance FoxO3a activity and cause skeletal muscle fiber atrophy (49).

Additionally, the roles of microRNAs in skeletal muscle damage and regeneration induced by atrophy have emerged (50). An additional novel study has demonstrated the downregulation of the miR-30 family in muscle disuse atrophy (51).

Although a lot of information has been reported about muscle wasting in cancer cachexia, few studies have been focused on whether muscle wasting in early cancer cachexia (ECC) differs from that in late cancer cachexia (LCC). It has been established that the development of tumors can be divided into different phases (52). Muscle wasting induced by tumors at different stages might be different. Bonetto et al (8) demonstrated that cancer cachexia had different severity, although the tumor-free body weight, muscle mass and certain molecule expression in their study were not significantly different between moderate and severe cancer cachexia. However, muscle wasting in LCC may, theoretically, have a more severe impact on cancer patients' quality of life than that in ECC, for example more body weight loss. Therefore, the differences between ECC and LCC remain poorly understood so far. The aim of the present study was to further reveal the different manifestations and molecular changes in muscle tissues from mice with ECC and LCC. To assess molecular alterations, we used two different cancer cachectic models, according to a previous study (53). Our results may provide some clues for preventing cancer cachexia at the early stage and improving cancer patients' quality of life.

\section{Materials and methods}

Cell culture and animal models. Colon-26 adenocarcinoma cells (C26 cells) (Medical Science Experimentation Center of Sun Yat-Sen University, China) and Lewis lung carcinoma cells (LLC cells) (Shanghai Branch of Chinese Academy of Science, China) were cultured in Dulbecco's modified Eagle's medium (DMEM) plus 10\% fetal bovine serum (FBS) with $1 \%$ penicillin/streptomycin at $37^{\circ} \mathrm{C}$ and $5 \% \mathrm{CO}_{2}$. Before injection of $\mathrm{C} 26$ cells into CD2F1 mice (C26 model) or injection of LLC cells into C57BL/6 mice (LLC model), cells were counted and resuspended at $5 \times 10^{7}$ cells $/ \mathrm{ml}$ in sterilized PBS. The right flanks of the mice were shaved, and they were administered a subcutaneous (s.c.) injection of either $5 \times 10^{6} \mathrm{C} 26$ cells or LLC cells suspended in $100 \mu \mathrm{l}$ sterilized PBS (tumor-bearing mice, TB mice) or $100 \mu 1$ sterilized PBS without cells (control mice, $\mathrm{CN}$ mice). Eight-week-old male CD2F1 or C57BL/6 mice were allocated randomly into one of four experimental groups: i) tumor-bearing mice in early cachexia (ECC mice); ii) tumorbearing mice in late cachexia (LCC mice); iii) ECC-matched control mice (ECC-CN mice); and iv) LCC-matched control mice (LCC-CN mice). The animals were monitored daily and were euthanized separately at 24 days (ECC and ECC-CN mice) and 36 days (LCC and LCC-CN mice) following injection $(7,9)$. Tumors, quadriceps, tibialis anterior, soleus, and gastrocnemius muscles, hearts, spleens, and epididymal fat were immediately harvested and weighed. For subsequent studies, tibialis anterior muscles were fixed in $4 \%$ paraformaldehyde, and the other tissues were quickly frozen in liquid nitrogen and stored at $-80^{\circ} \mathrm{C}$. All experiments were approved by the Animal Care and Use Committee of Tongji Medical College of Huazhong University of Science and Technology.

Myofiber cross-sectional area. To determine the myofiber cross-sectional area (CSA), hematoxylin and eosin (H\&E) staining was performed on a middle cross-section of the tibialis anterior. Images were acquired using a digital camera and were quantified using ImageJ software (NIH, Bethesda, MD, USA). Within each section, five view fields with 100 myofibers per field were measured (10).

Immunofluorescence. To visualize the outlines of myofibers, $10 \mu \mathrm{m}$ sections were obtained from the middle of the tibialis anterior. The sections were then incubated with Alexa Fluor 350-conjugated wheat germ agglutinin (Invitrogen, Carlsbad, CA, USA) for $2 \mathrm{~h}$ and subsequently washed in PBS. Images were acquired using a digital camera $(3,49)$. Representative view fields were elected and recorded.

Real-time reverse transcription PCR. RNA was extracted from quadriceps muscles using TRIzol reagent (Invitrogen) according to the manufacturer's instructions. The concentration 
Table I. Changes in tumor-free body mass, muscle mass, organ mass, and fat mass in the C26 model.

\begin{tabular}{|c|c|c|c|c|c|c|}
\hline & \multicolumn{3}{|c|}{24 days } & \multicolumn{3}{|c|}{36 days } \\
\hline & $\begin{array}{l}\text { Control } \\
(\mathrm{CN})\end{array}$ & P-value & $\begin{array}{l}\text { C26 tumor bearing } \\
\text { (TB) }\end{array}$ & $\begin{array}{l}\text { Control } \\
(\mathrm{CN})\end{array}$ & P-value & $\begin{array}{l}\text { C26 tumor bearing } \\
\text { (TB) }\end{array}$ \\
\hline $\mathrm{n}$ & 4 & & 5 & 4 & & 5 \\
\hline Tumor-free body mass (g) & $27.74 \pm 0.74$ & $0.001^{\mathrm{c}}$ & $22.92 \pm 0.73$ & $27.15 \pm 0.62$ & $0.001^{\mathrm{e}}$ & $19.60 \pm 0.90$ \\
\hline Quadriceps (mg) & $134.90 \pm 7.30$ & $0.001^{\mathrm{c}}$ & $114.97 \pm 7.69$ & $161.93 \pm 20.82$ & $0.001^{\mathrm{e}}$ & $80.09 \pm 13.07$ \\
\hline Tibialis anterior (mg) & $51.76 \pm 3.75$ & $0.01^{\mathrm{b}}$ & $44.93 \pm 5.03$ & $56.24 \pm 7.39$ & $0.001^{\mathrm{e}}$ & $31.89 \pm 6.43$ \\
\hline Gastrocnemius (mg) & $128.56 \pm 10.80$ & $0.01^{\mathrm{b}}$ & $111.99 \pm 6.67$ & $144.61 \pm 10.06$ & $0.001^{\mathrm{e}}$ & $83.98 \pm 10.89$ \\
\hline Soleus (mg) & $6.73 \pm 2.46$ & $0.05^{\mathrm{a}}$ & $4.90 \pm 0.84$ & $6.46 \pm 1.80$ & $0.01^{\mathrm{d}}$ & $4.47 \pm 0.85$ \\
\hline Heart (mg) & $139.60 \pm 6.05$ & $0.05^{\mathrm{a}}$ & $120.94 \pm 13.33$ & $149.65 \pm 13.61$ & $0.001^{\mathrm{e}}$ & $87.26 \pm 3.28$ \\
\hline Spleen (mg) & $77.83 \pm 5.14$ & $0.001^{\mathrm{c}}$ & $218.84 \pm 45.36$ & $90.33 \pm 4.14$ & $0.001^{\mathrm{e}}$ & $293.70 \pm 49.96$ \\
\hline Epididymal fat (mg) & $559.78 \pm 114.77$ & $0.001^{\mathrm{c}}$ & $194.54 \pm 68.95$ & $401.48 \pm 60.37$ & $0.001^{\mathrm{e}}$ & $33.24 \pm 14.99$ \\
\hline
\end{tabular}

${ }^{\mathrm{a}}$ Twenty-four days-CN vs. 24 days-TB; ${ }^{\mathrm{b}} 24$ days-CN vs. 24 days-TB; ${ }^{\mathrm{c}} 24$ days-CN vs. 24 days-TB; ${ }^{\mathrm{d}} 36$ days-CN vs. 36 days-TB; ${ }^{\mathrm{e}} 36$ days-CN vs. 36 days-TB.

and purity of the RNA solution were determined by Epoch microplate spectrophotometer (BioTek Instruments, Inc., Winooski, VT, USA). RNA (1 $\mu \mathrm{g})$ was used for reverse transcription. Reverse transcription of mRNA was performed using a RevertAid First-Strand cDNA Synthesis kit (Thermo Fisher Scientific, Inc., Rockford, IL, USA) in a total reaction volume of $10 \mu \mathrm{l}$. Dilution (1:10) of the RT product was used as template for the quantitative real-time PCR (qPCR). qPCR was performed with the 2X SYBR-Green Mix (Thermo Fisher Scientific) using a LightCycler ${ }^{\circledR} 480$ (Roche Diagnostics, Mannheim, Germany) in a total reaction volume of $10 \mu \mathrm{l}$ with the primers from Sangon Biotech, Co., Ltd. (Shanghai, China). The amplification procedure was $95^{\circ} \mathrm{C}$ pre-denaturation for $10 \mathrm{~min}$ followed by $95^{\circ} \mathrm{C}$ for $15 \mathrm{sec}, 60^{\circ} \mathrm{C}$ for $10 \mathrm{sec}$ and $72^{\circ} \mathrm{C}$ for $30 \mathrm{sec}$ for a total of 40 cycles. The data were normalized to glyceraldehyde-3-phosphate dehydrogenase (GAPDH) expression and the relative expression was calculated using the formula: $2^{-\Delta \mathrm{Ct}}\left(\Delta \mathrm{Ct}=\mathrm{Ct}_{\text {gene }}-\mathrm{Ct}_{\mathrm{GAPDH}}\right)$. The primer sequences were as follows: Myostatin: F-AGTGGATCTAAATGAGGG CAGT and R-GTTTCCAGGCGCAGCTTAC; PGC1 $\alpha$ : F-AA CCACACCCACAGGATCAGA and R-TCTTCGCTTTAT TGCTCCATGA; FoxO3a: F-GCAAGCCGTGTACTGTGGA and R-CGGGAGCGCGATGTTATCC; MuRF1: F-AGCAT CAAGATCCGTCTGACA and R-CCAGAGCCGTCCACA ACAAT; Atrogin1: F-ACACATCCTTATGCACACTGG and R-TCTCCATCCGATACACCCACA; GAPDH: F-GGTGAA GGTCGGAGTCAACGG and R-GAGGTCAATGAAGGGG TCATTG.

Western blotting. The quadriceps muscles were homogenized, and total protein was extracted using RIPA protein lysis buffer (P1003; Beyotime Institute of Biotechnology, Nantong, China) with freshly added protease inhibitor cocktail and phenylmethylsulphonyl fluoride (PMSF). The protein concentration of the samples was measured using BCA method. A total of $80 \mu \mathrm{g}$ of protein was subjected to a $10 \%$ SDS-PAGE gel to separate the proteins by gel electrophoresis, and they were then transferred onto polyvinylidene fluoride (PVDF) $(0.45 \mu \mathrm{m}$;
Millipore, Boston, MA, USA) membranes. The membranes were blocked for $1 \mathrm{~h}$ at $37^{\circ} \mathrm{C}$ in $5 \%(\mathrm{w} / \mathrm{v})$ non-fat dried skim milk (blocking buffer) and incubated with primary antibodies in blocking buffer overnight at $4^{\circ} \mathrm{C}$. The primary antibodies were as follows: anti-atrogin1 antibody (\#AP2041), purchased from ECM Biosciences, Versailles, KY, USA; anti-PGC1 $\alpha$ antibody (ab54481), purchased from Abcam, Cambridge, MA, USA; anti-Phospho-FoxO3a (\#9466) and anti-FoxO3a (\#2497) antibodies obtained from Cell Signaling Technology, Danvers, MA, USA; anti-C/EBP $\beta$ (sc-7962), anti-HDAC1 (sc-7872), anti-HDAC2 (sc-7899), and anti-HDAC3 (sc-11417) antibodies acquired from Santa Cruz Biotechnology, Santa Cruz, CA, USA. The membranes were washed and incubated with the appropriate horseradish peroxidase-conjugated secondary antibody (Invitrogen) in blocking buffer for $2 \mathrm{~h}$ at room temperature. Finally, the membranes were washed before detection. Quantitative analyses of protein expression were performed using ImageJ software (25).

Statistical analysis. All values were represented as the mean \pm standard error (SEM) unless stated otherwise. Differences between group means were determined using the Student's t-test with Graphpad Prism 5 unless otherwise specified. A two-sided P-value of $<0.05$ was considered to indicate statistically significant result.

\section{Results}

Body weights of LCC mice were decreased for C26 model but not LLC model. For the C26 model mice, at 24 days following C26 tumor implantation, the body weights of the ECC-CN and ECC mice were both increased (Fig. 1A). From the 30th day, the body weights of the LCC mice started to decrease, and this trend was maintained until the 36th day, when the mice in this group were sacrificed (Fig. 1B). For the LLC model mice, in contrast with the $\mathrm{C} 26$ model mice, the body weights of both the ECC and LCC mice consistently increased until day 36 (Fig. 1C and D). Nevertheless, the ECC mice had already 

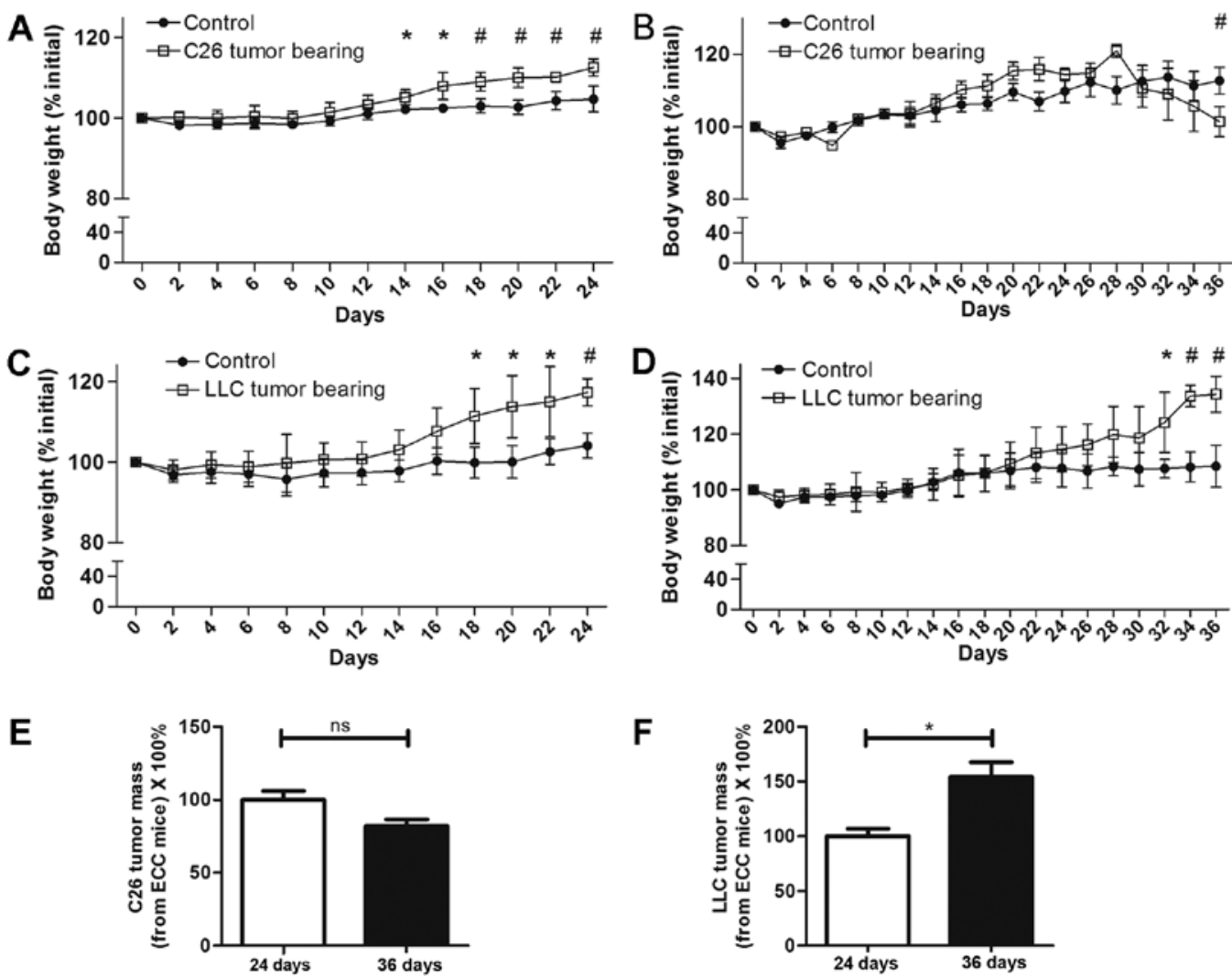

Figure 1. Body weight curves and tumor mass in each group. Body weights of CD2F1 mice injected subcutaneously with C26 cells or PBS were recorded for (A) 24 days and (B) 36 days. Body weights of C57BL/6 mice injected subcutaneously with LLC cells or PBS were recorded for (C) 24 days and (D) 36 days. (E) The tumor masses from the C26 model ECC and LCC mice. (F) The tumor masses from the LLC model ECC and LCC mice. (A-D) All body weights were normalized to the percentage of the initial body weight. (E and F) The tumor masses of TB mice were normalized to the percentage of the tumor masses of their matched ECC mice. ${ }^{*} \mathrm{P}<0.05,{ }^{\#} \mathrm{P}<0.01$.

Table II. Changes in tumor-free body mass, muscle mass, organ mass, and fat mass in the LLC model.

\begin{tabular}{|c|c|c|c|c|c|c|}
\hline & \multicolumn{3}{|c|}{24 days } & \multicolumn{3}{|c|}{36 days } \\
\hline & $\begin{array}{l}\text { Control } \\
(\mathrm{CN})\end{array}$ & P-value & $\begin{array}{l}\text { C26 tumor bearing } \\
\text { (TB) }\end{array}$ & $\begin{array}{l}\text { Control } \\
\text { (CN) }\end{array}$ & P-value & $\begin{array}{l}\text { C26 tumor bearing } \\
\text { (TB) }\end{array}$ \\
\hline $\mathrm{n}$ & 4 & & 6 & 4 & & 6 \\
\hline Tumor-free body mass (g) & $22.61 \pm 1.16$ & $0.05^{\mathrm{a}}$ & $19.87 \pm 1.39$ & $23.19 \pm 2.10$ & $0.001^{\mathrm{e}}$ & $16.49 \pm 1.05$ \\
\hline Quadriceps (mg) & $117.04 \pm 8.50$ & $0.01^{\mathrm{b}}$ & $100.13 \pm 10.23$ & $116.18 \pm 6.16$ & $0.001^{\mathrm{e}}$ & $64.49 \pm 11.48$ \\
\hline Tibialis anterior (mg) & $50.88 \pm 6.95$ & $0.05^{\mathrm{a}}$ & $44.24 \pm 5.69$ & $50.26 \pm 4.91$ & $0.001^{\mathrm{e}}$ & $30.27 \pm 4.32$ \\
\hline Gastrocnemius (mg) & $131.11 \pm 7.58$ & $0.05^{\mathrm{a}}$ & $119.15 \pm 12.54$ & $134.11 \pm 7.04$ & $0.001^{\mathrm{e}}$ & $85.55 \pm 5.83$ \\
\hline Soleus (mg) & $7.73 \pm 0.89$ & $0.001^{\mathrm{c}}$ & $6.29 \pm 0.55$ & $7.10 \pm 0.64$ & $0.001^{\mathrm{e}}$ & $5.34 \pm 0.67$ \\
\hline Heart (mg) & $100.23 \pm 5.61$ & & $103.05 \pm 8.24$ & $142.80 \pm 33.31$ & & $124.58 \pm 35.09$ \\
\hline Spleen $(\mathrm{mg})$ & $72.05 \pm 7.50$ & $0.001^{\mathrm{c}}$ & $198.63 \pm 30.27$ & $67.90 \pm 13.51$ & $0.05^{\mathrm{d}}$ & $220.72 \pm 85.35$ \\
\hline Epididymal fat (mg) & $339.38 \pm 97.72$ & $0.05^{\mathrm{a}}$ & $159.32 \pm 100.88$ & $465.55 \pm 121.66$ & $0.001^{\mathrm{e}}$ & $18.16 \pm 5.69$ \\
\hline
\end{tabular}

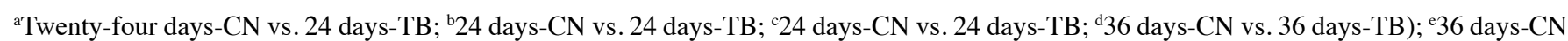
vs. 36 days-TB.

developed cancer cachexia, as the tumor-free body masses of these mice were significantly decreased for both the C26 and LLC models. Interestingly, the tumor masses of the LCC mice were higher than that of ECC mice in LLC model. But no significant differences existed between the ECC mice and LCC mice in C26 model (Fig. 1E and F).
The tumor-free masses of the ECC mice were reduced by $\sim 18$ and $13 \%$ compared with those of ECC-CN mice for the C26 and LLC models, respectively. A similar finding was observed for the LCC mice, but with higher rates of reduction ( 28 and $29 \%$ compared with the C26 and LLC model LCC-CN mice, respectively). The tumor-free masses of the 

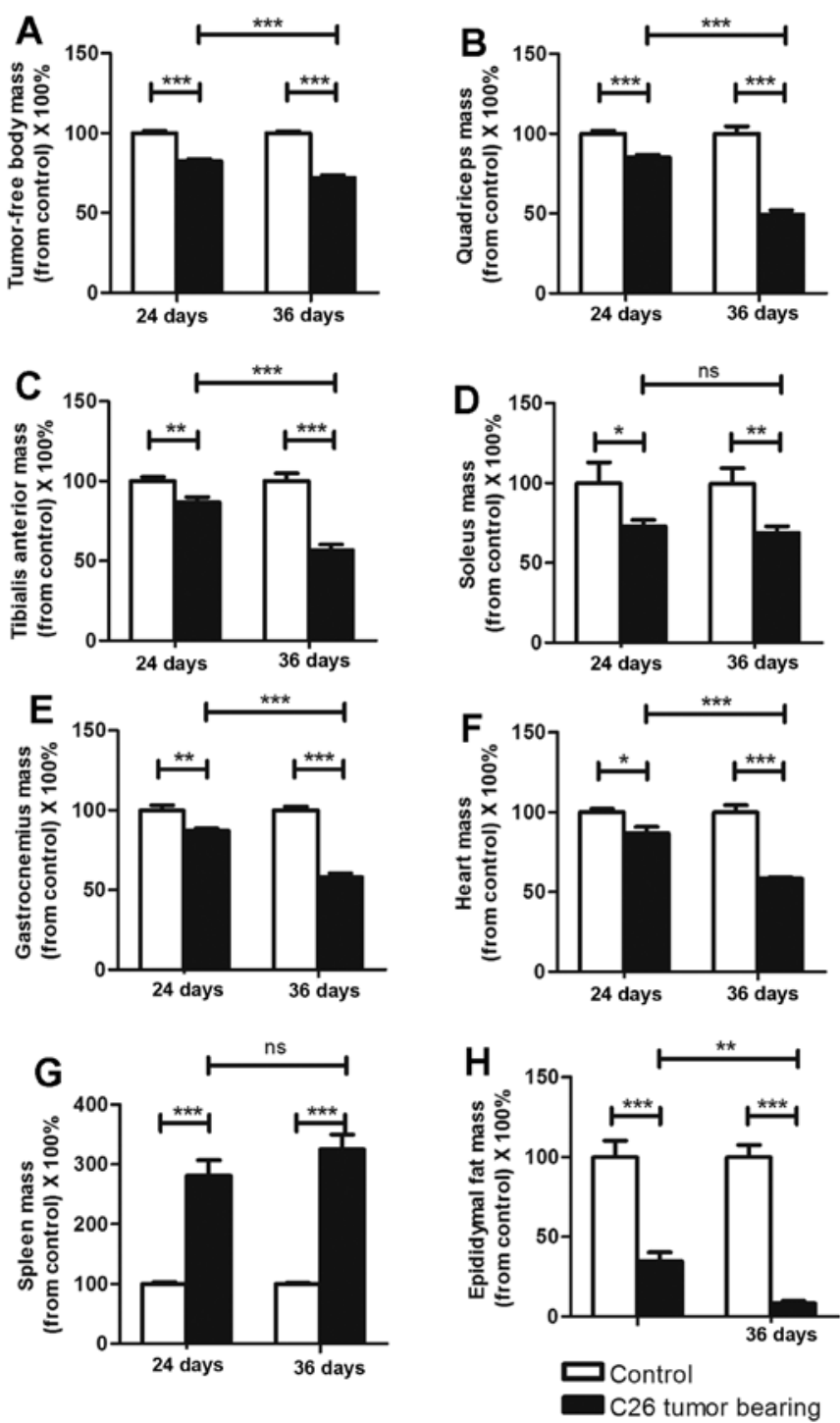

Figure 2. The tumor-free body masses and masses of various tissues in C26 model $\mathrm{CN}$ and TB mice. The (A) tumor-free body, (B) quadriceps, (C) tibialis anterior, (D) soleus, (E) gastrocnemius, (F) heart, (G) spleen, and (H) epididymal fat masses from C26 model ECC and LCC mice. (A-H) The masses of tissues from the TB mice were normalized to the percentage of the masses of the tissues from their matched $\mathrm{CN}$ mice. ${ }^{*} \mathrm{P}<0.05,{ }^{* *} \mathrm{P}<0.01,{ }^{* * *} \mathrm{P}<0.001$ ).

LCC mice were obviously less than those of the ECC mice for both models (Figs. 2A and 3A).

For the above reasons, we defined the TB mice sacrificed on the 24th day as ECC mice (their tumor-free body masses were decreased by $<20 \%$ ) and the TB mice sacrificed on the 36 th day as LCC mice (their tumor-free body masses were decreased by $>20 \%$ ).

The mass variations in organs and muscles differed between the ECC and LCC mice. As previously reported, C26 cachexia results in skeletal muscle, epididymal adipose and heart mass losses (7). The masses of the organs and muscles harvested from the C26 and LLC model mice are listed in Tables I and II. We obtained similar findings for these two models (Figs. 2 and 3), except that the heart mass did not exhibit a substantial change (Fig. 3F) in the LLC model. We found that the LCC mice had much greater losses of muscle
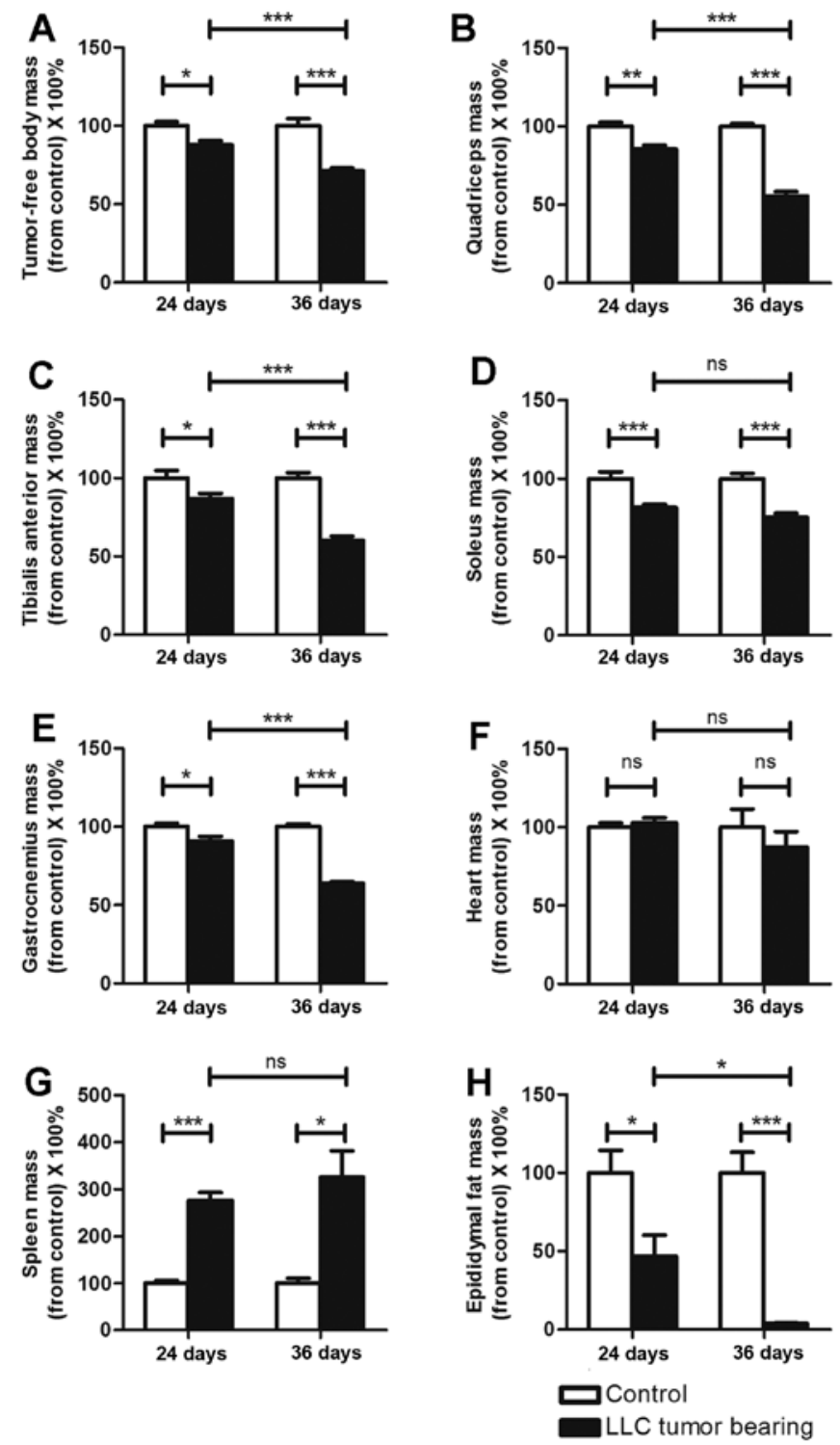

Figure 3. The tumor-free body masses and masses of various tissues in LLC model $\mathrm{CN}$ and TB mice. The (A) tumor free body, (B) quadriceps, (C) tibialis anterior, (D) soleus, (E) gastrocnemius, (F) heart, (G) spleen, and (H) epididymal fat masses from LLC model ECC and LCC mice. (A-H) The masses of tissues from the TB mice were normalized to the percentage of the masses of the tissues from their matched $\mathrm{CN}$ mice. ${ }^{*} \mathrm{P}<0.05,{ }^{* *} \mathrm{P}<0.01,{ }^{* * *} \mathrm{P}<0.001$.

and epididymal adipose mass than the ECC mice for both models (Figs. 2 and 3), except for the soleus muscle mass (Figs. 2D and 3D). These data further demonstrated that the LCC mice suffered from more severe cancer cachexia than the ECC mice.

C26 cancer cachexia has been reported to result in a large increase in the mass of the spleen (3). This conclusion is consistent with our results (Fig. 2G), and we obtained the same results with the LLC model (Fig. 3G). However, the spleen masses did not significantly differ between the ECC and LCC mice for either model (Figs. $2 \mathrm{G}$ and $3 \mathrm{G}$ ). Additionally, the heart masses did not significantly differ between the ECC or LCC mice and their matched $\mathrm{CN}$ mice for the LLC model (Fig. 3F). These results differed from those for the $\mathrm{C} 26$ model mice but are consistent with those of a previous study (14). 


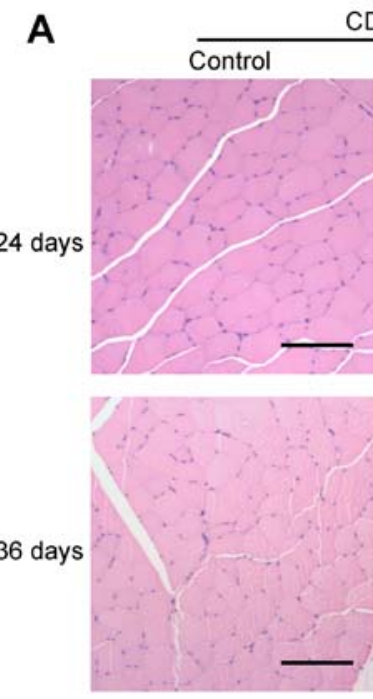

CD2F1
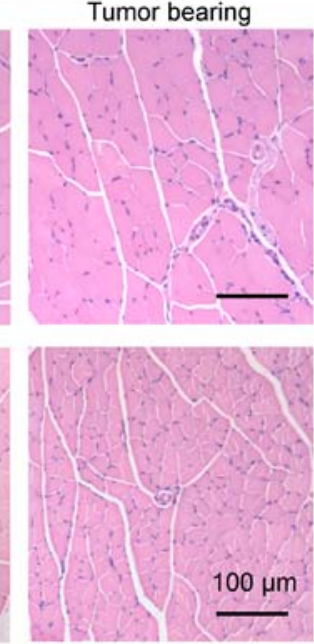

B
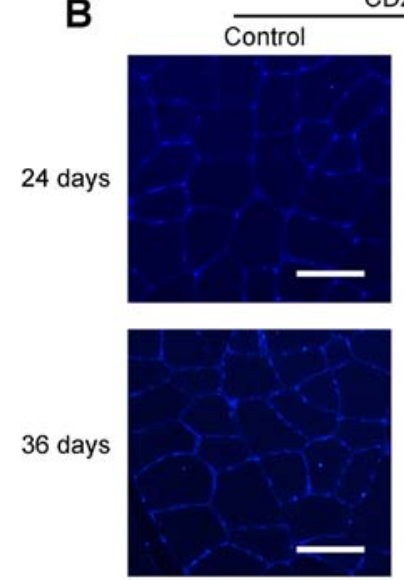

$\mathrm{CD} 2 \mathrm{~F} 1$
Tumor bearing
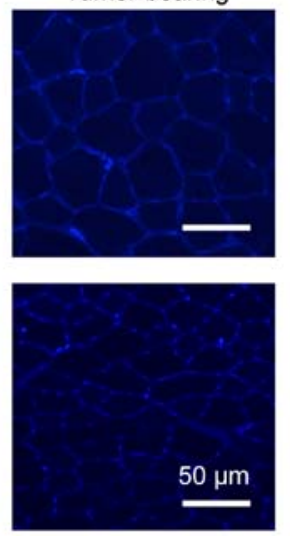
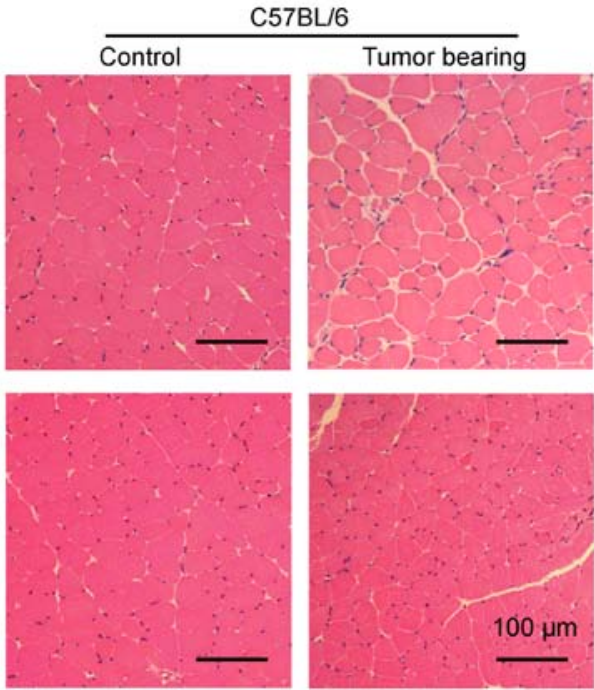

C57BL/6

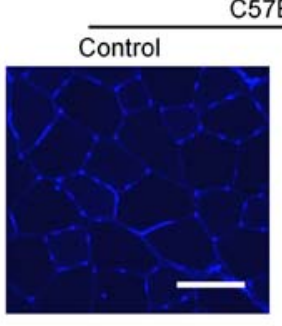

Tumor bearing
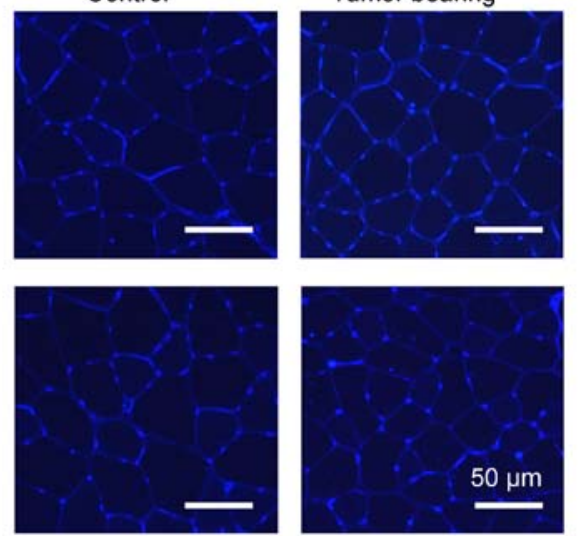

Figure 4. Middle cross sections of tibialis anterior muscles from mice in each group. (A) Representative images of H\&E-stained cross sections of tibialis anterior muscles from mice in each group. Bar represents $100 \mu \mathrm{m}$. (B) Representative images of cross sections of tibialis anterior muscles incubated with wheat germ agglutinin to allow for visualization of muscle fiber membranes (blue). Bar represents $50 \mu \mathrm{m}$.

The muscle fiber size was smaller in LCC mice than in ECC mice. Representative images of H\&E-stained tibialis anterior middle cross sections from the mice in each group are shown in Fig. 4A. To better visualize the outlines of muscle fibers, skeletal muscle cross sections taken from tibialis anterior muscles were incubated with fluorescently labeled wheat germ agglutinin (Fig. 4B). The average muscle fiber CSAs declined by 15 and $45 \%$ in the ECC and LCC mice, respectively, compared with their matched $\mathrm{CN}$ mice for the $\mathrm{C} 26$ model (Fig. 5A), and these values declined by 13 and $43 \%$, respectively, for the LLC model (Fig. 5B). Additionally, the changes in muscle mass were confirmed by analyses of the size distributions of myofibers in each group. These results indicated that the muscle fiber CSA of the LCC mice, but not the ECC mice, was obviously less than that of the LCC-CN mice for both models (Fig. 5C and D).

The levels of several muscle mRNAs differed between the ECC and LCC mice. To determine the mRNA levels of some molecules involved in muscle wasting, five prominent molecules were selected for analysis in each group. The mRNA levels of these molecules did not obviously change in the ECC mice of both models, except for that of atrogin1, which was increased in the ECC mice compared with the ECC-CN mice for the $\mathrm{C} 26$ model, but not the LLC model (Fig. 6A and C). In contrast with the ECC mice, the levels of several mRNAs were increased in the muscles from the LCC mice of the two models. The mRNA levels of atrogin 1 and FoxO3a were increased in the LCC mice of both models (Fig. 6B and D). Additionally, the mRNA expression of myostatin was increased in the muscles from the LLC model LCC mice (Fig. 6D). A previous study revealed that the mRNA level of PGC1 $\alpha$ is consistently decreased (25). However, we found no significant difference in this mRNA level between the $\mathrm{CN}$ and $\mathrm{TB}$ mice of either model (Fig. 6).

Several muscle protein levels differed between the ECC and LCC mice. To explore the underlying mechanism of the increased severity of cancer cachexia in the LCC mice compared with the ECC mice, the protein levels of some crucial molecules involved in muscle wasting, such as atrogin1, FoxO3a, PGC1 $\alpha, \mathrm{C} / \mathrm{EBP} \beta$ and class I HDACs, were determined. The protein level of atrogin1 was increased in the TB mice compared with their matched $\mathrm{CN}$ mice for both models (Figs. 7 and 8). We subsequently detected the expression of the molecules that may regulate the expression of atrogin1. The 

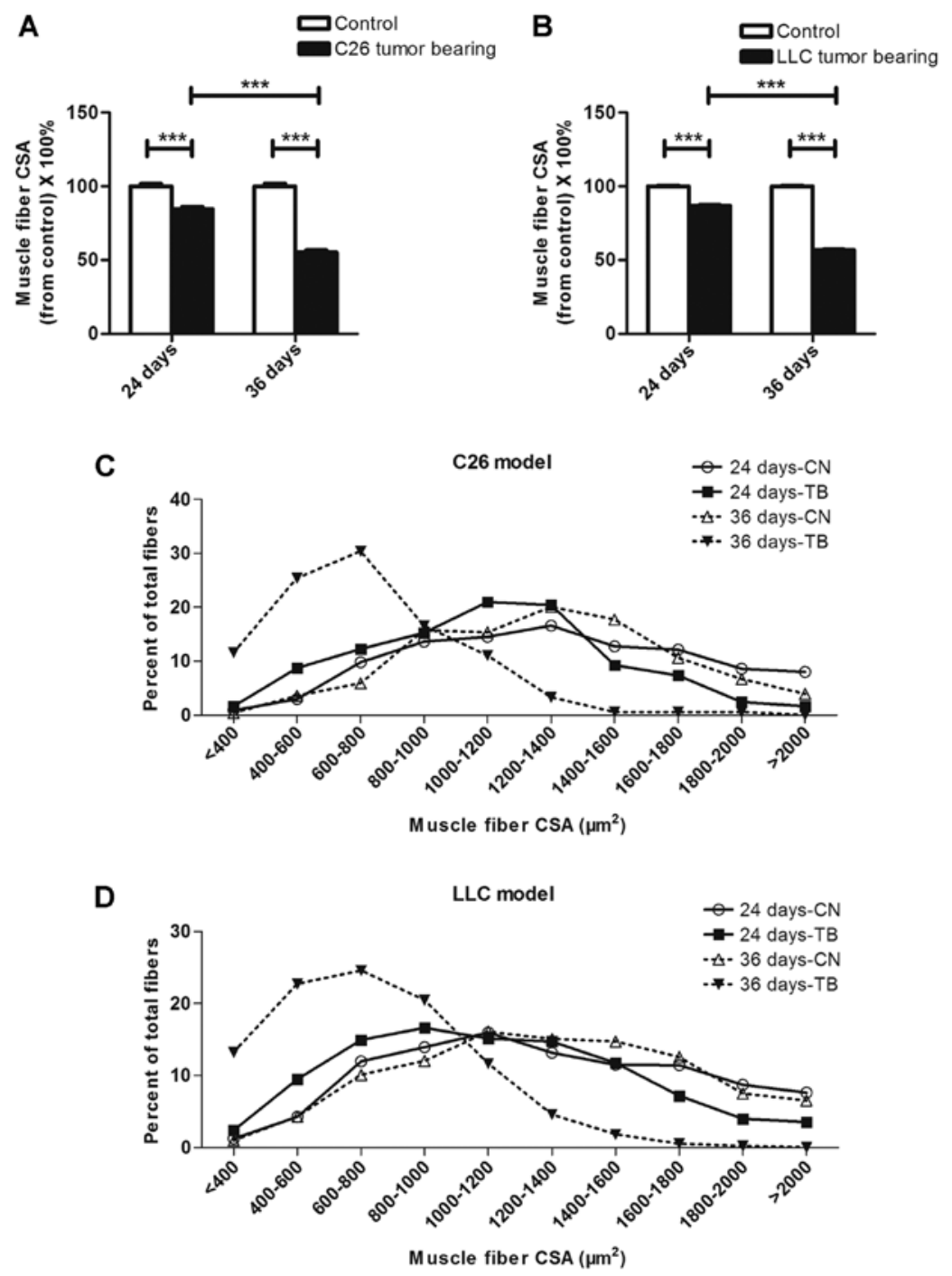

Figure 5. Cross-sectional areas of myofibers. The average CSAs of myofibers in tibialis anterior muscles from mice of the (A) C26 model and (B) LLC model. Analysis of the size distributions of myofibers in tibialis anterior muscles from mice of the (C) C26 model and (D) LLC model. (A and B) The average CSA of myofibers in the TB mice were normalized to the percentage of the average CSA of myofibers in their matched CN mice. ${ }^{* * *} \mathrm{P}<0.001$.

FoxO3a (not phospho-FoxO3a) protein level was also found to be increased in the muscles from the TB mice compared with their matched $\mathrm{CN}$ mice for both models (Figs. 7 and 8). The PGCl $\alpha$ protein level was obviously decreased in the LCC mice compared with the LCC-CN mice, but no significant difference was observed between the ECC and ECC-CN mice (Figs. 7 and 8). In contrast, the C/EBP $\beta$ protein level was obviously increased in the LCC mice compared with the LCC-CN mice, but no significant difference was detected between the ECC and ECC-CN mice (Figs. 7 and 8).

Furthermore, the protein levels of three class I HDACs were determined, and those of HDAC 1 and HDAC 3 were found to be slightly increased in the LCC mice compared with the LCC-CN mice for both models, while only HDAC2 was increased in the LLC model LCC mice (Figs. 7 and 8).

\section{Discussion}

ECC and LCC definitions suitable for the study of muscle wasting were determined. Cancer cachexia has been widely studied. A previous report demonstrated that lipid metabolism in adipose tissue differs between C26 model ECC and LCC mice. ECC was defined by the author as occurring no more than 12 days following C26 tumor implantation, when the white adipose tissue mass in cachectic mice is moderately reduced (34-42\%) and weight loss is $<10 \%$ of the initial body weight (54). Normally, loss of fat always occurs before muscle wasting in cancer cachexia. Therefore, in the present study, we prolonged the period defined as ECC for the optimal assessment of muscle wasting. We found that this definition was suitable for research of muscle wasting in the C26 and LLC models.

Muscle wasting in LCC should not be overlooked. Prior to this study, many research groups focused on muscle wasting only in ECC. Thus, we questioned whether the molecules regulating muscle wasting in LCC are similar to those in ECC. The aim of the present study was to determine the differences between muscle wasting in ECC and LCC.

The tissue changes differed between the ECC and LCC mice. The alterations in the tumor-free body masses, the masses of 

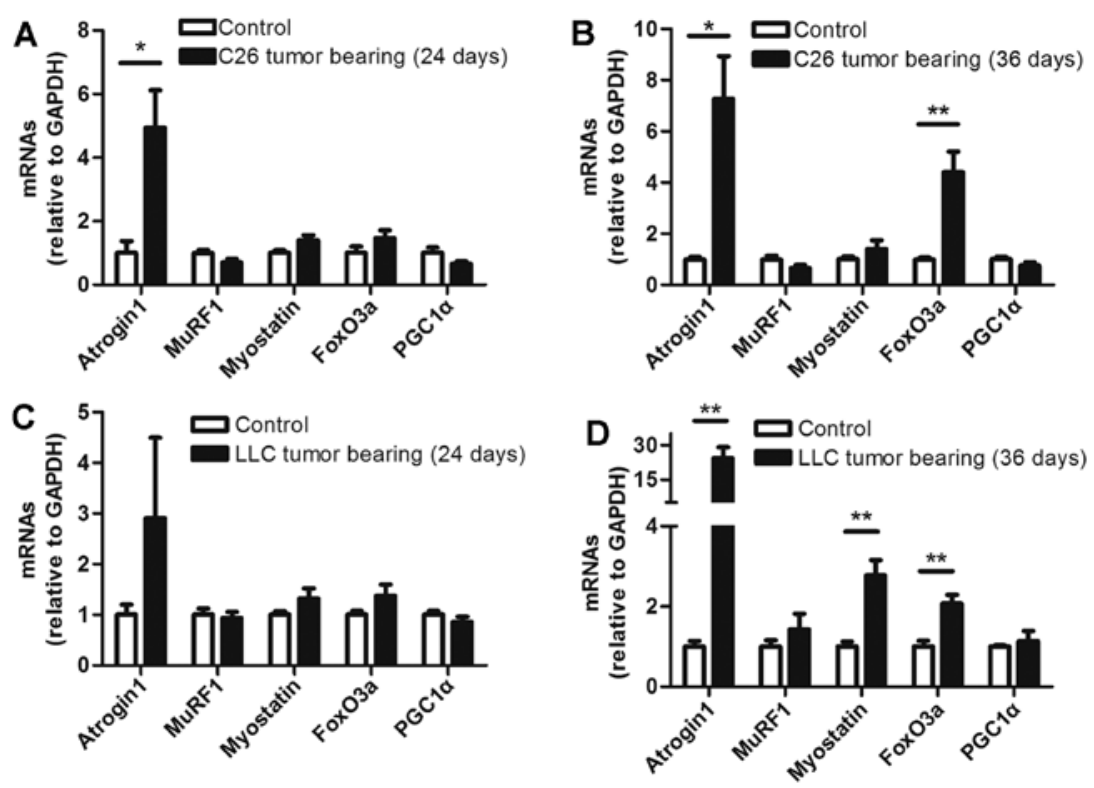

Figure 6. The mRNA levels of genes involved in muscle wasting. (A) The mRNA levels of genes in muscles from C26 model ECC mice. (B) The mRNA levels of genes in muscles from C26 model LCC mice. (C) The mRNA levels of genes in muscles from LLC model ECC mice. (D) The mRNA levels of genes in muscles from LLC model LCC mice. (A-D) The data for the TB mice were normalized to those for their matched $\mathrm{CN}$ mice. ${ }^{*} \mathrm{P}<0.05,{ }^{* * *} \mathrm{P}<0.01,{ }^{* * * *} \mathrm{P}<0.001$.

A
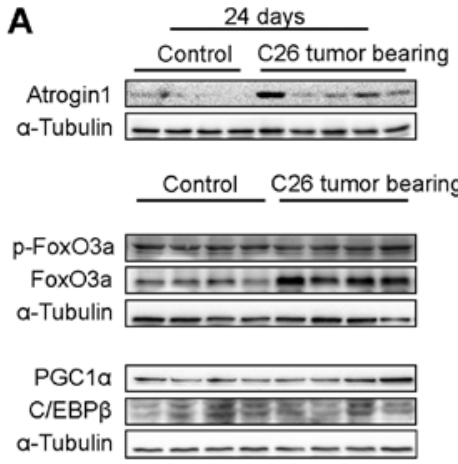

HDAC1

HDAC2

HDAC3

a-Tubulin
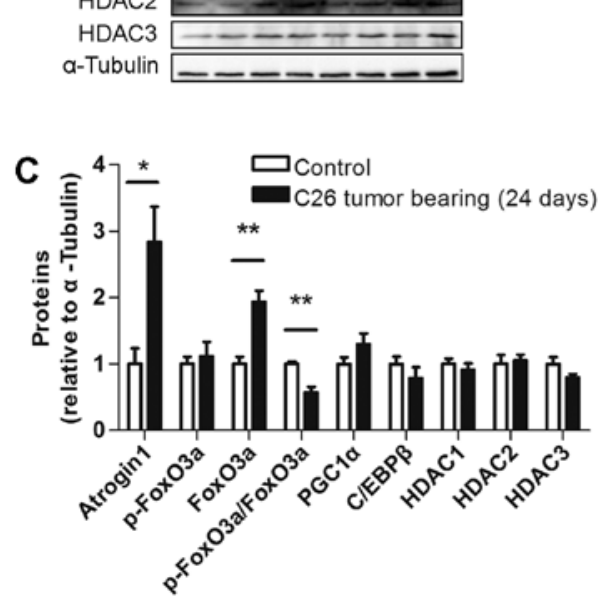

B
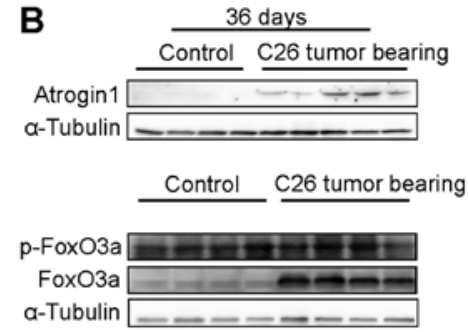

PGC1a

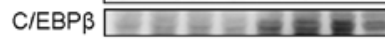

a-Tubulin $-\ldots$

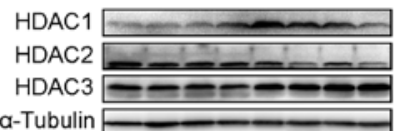

a-Tubulin

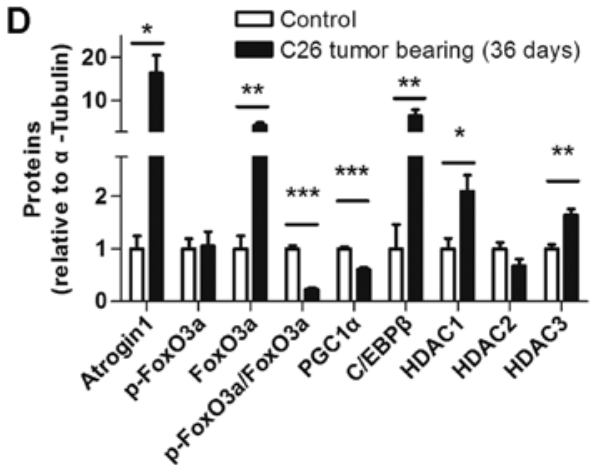

Figure 7. The protein levels of genes involved in muscle wasting in $\mathrm{C} 26$ model mice. The protein levels of atrogin1, p-FoxO3a, FoxO3a, PGC1 $\alpha, \mathrm{C} / \mathrm{EBP} \beta$, HDAC1, HDAC2 and HDAC3 in muscles from C26 model (A) ECC mice and (B) LCC mice. Densitometric analysis of molecules detected by western blot analysis in muscles from C26 model (C) ECC mice and (D) LCC mice. (C and D) The data for the TB mice were normalized to those for their matched CN mice. ${ }^{*} \mathrm{P}<0.05,{ }^{* *} \mathrm{P}<0.01,{ }^{* * *} \mathrm{P}<0.001$.

various tissues and the cross-sectional areas (CSAs) of muscle fibers differed between the ECC and LCC mice and their matched $\mathrm{CN}$ mice. These results demonstrated that obvious differences existed between ECC and LCC. From this point 
A
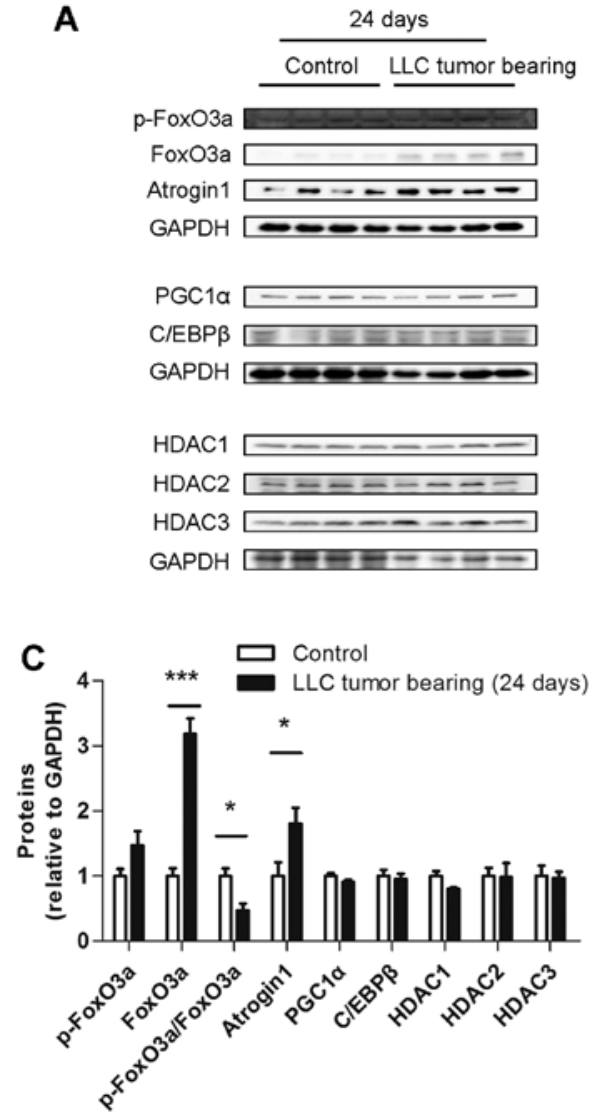

B

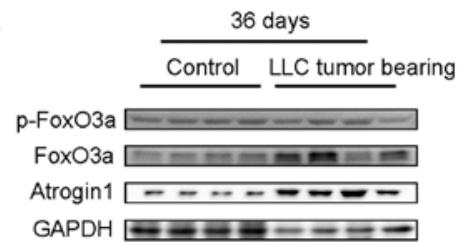

PGC1a

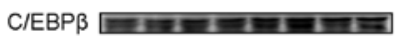
GAPDH

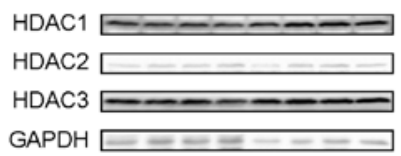

GAPDH

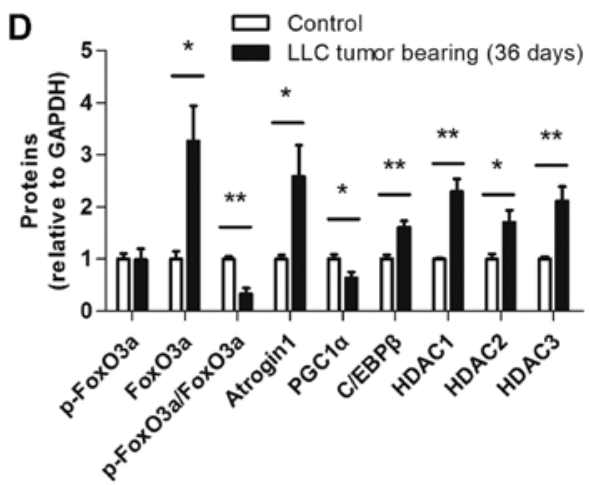

Figure 8. The protein levels of genes involved in muscle wasting in LLC model mice. The protein levels of atrogin1, p-FoxO3a, FoxO3a, PGC1 $\alpha$, C/EBP $\beta$, HDAC1, HDAC2 and HDAC3 in muscles from LLC model (A) ECC mice and (B) LCC mice. Densitometric analysis of molecules detected by western blot analysis in muscles from LLC model (C) ECC mice and (D) LCC mice. (C and D) The data for the TB mice were normalized to those for their matched CN mice. ${ }^{*} \mathrm{P}<0.05,{ }^{* * *} \mathrm{P}<0.01,{ }^{* * * *} \mathrm{P}<0.001$.

\begin{tabular}{|c|c|c|c|}
\hline (1) & Position $358-365$ of atrogin 13 UTR & $5^{\prime}$ & ...CAAGAUGGAACACUCUGUUUACA \\
\hline & mmu-miR-30c & $3^{\prime}$ & CGACUCUCACAUCCUACAAAUGU \\
\hline (2) & Position 109-115 of FoxO3a 3' UTR & $5^{\prime}$ & $\begin{array}{c}\ldots \text { AGUGGACAGUGAUCC--GUUUACAG... } \\
11 \| 1\end{array}$ \\
\hline & mmu-miR-30c & $3^{\prime}$ & CGACUCUCACAUCCUACAAAUGU \\
\hline (3) & Position 98-104 of HDAC3 3' UTR & $5^{\prime}$ & ...UGGGUACCCCCAGGGUGUUUACU... \\
\hline & mmu-miR-30c & $3^{\prime}$ & CGACUCUCACAUCCUACAAAUGU \\
\hline (4) & Position 60-80 of PGC1 $5^{\prime}$ ' UTR & $5^{\prime}$ & $\begin{array}{c}. . . \text { GGTTGGAGTCCA--ATGTTTATT... } \\
|||||||||1| 1|| \mid\end{array}$ \\
\hline & mmu-miR-30c & $3^{\prime}$ & CGACUCUCACAUCCUACAAAUGU \\
\hline
\end{tabular}
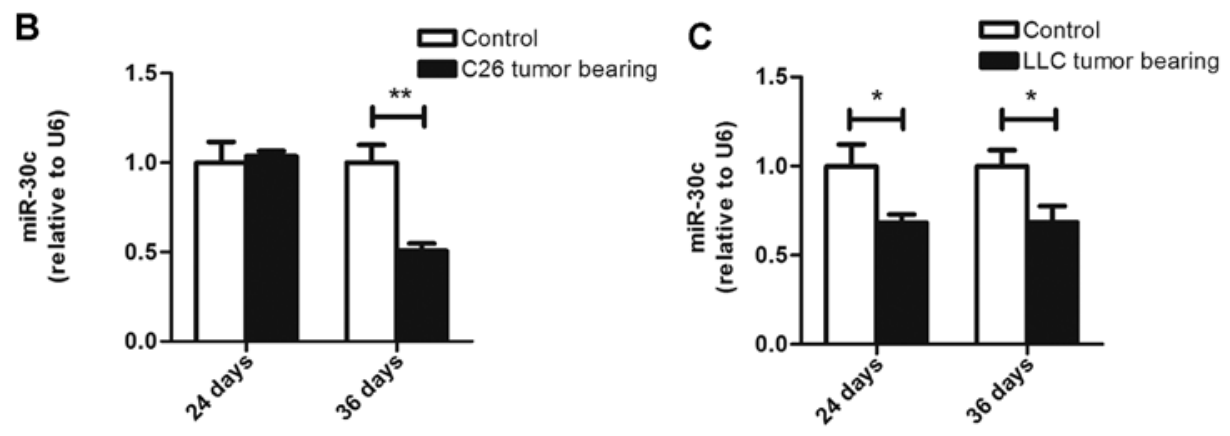

Figure 9. The expression of miR-30c in muscles from mice in each group. (A) Prediction of the conserved miR-30c sites in the 3'UTRs of atrogin1, FoxO3a, and HDAC3 was performed using TargetScan. Prediction of the conserved miR-30c site in the 5'UTR of PGC1 $\alpha$ was performed using RegRNA. (B) The expression of miR-30c in muscles from C26 model ECC and LCC mice. (C) The expression of miR-30c in muscles from LLC model ECC and LCC mice. (B and C) The data for the TB mice were normalized to those for their matched $\mathrm{CN}$ mice. ${ }^{*} \mathrm{P}<0.05,{ }^{* *} \mathrm{P}<0.01$. 
of view, the definitions of ECC and LCC in the C26 and LLC models were also feasible.

The expression changes differed between the ECC and LCC mice. Myostatin plays an important role in many types of muscle atrophy (19). However, its mRNA level was only altered in the muscles from the LLC model LCC mice. This result might indicate that the mRNA expression of myostatin is not a sensitive indicator of muscle wasting in our models, especially in the $\mathrm{C} 26$ model. Although the mRNA level of myostatin did not obviously change, the expression of the downstream molecule FoxO3a was altered. The protein level of FoxO3a was increased in the TB mice of both models, and its mRNA level was only increased in the LCC mice, but not in the ECC mice. Atrogin1 and MuRF1 are both important E3 ubiquitin ligases involved in muscle wasting (28), but only the mRNA level of atrogin1, and not that of MuRF1, was increased in our models. In addition, the protein level of atrogin1 was increased in the TB mice of both models. These results suggested that atrogin1 might be the more crucial gene involved in muscle wasting in our models. The altered atrogin1 expression directly induced muscle wasting in the TB mice, and no significant difference in its expression was detected between the ECC and LCC mice. Collectively, the myostatin-FoxO3a-atrogin1 axis indeed played an important role in muscle wasting in our models.

Currently, increasing numbers of studies are focusing on the molecules that affect the myostatin-FoxO3a-atrogin1 axis. We found that the molecules involved in muscle wasting were not exactly the same in the ECC and LCC mice of each model. In addition, we focused on the molecules that were altered only in the muscles from the LCC mice. Although the mRNA level of PGCl $\alpha$ was not altered in the TB mice, its protein level was decreased in the LCC mice, but not in the ECC mice, of both models. These results indicated that C/EBP $\beta$, HDAC1 and HDAC3 might play roles in promoting cancer cachexia, especially during the late stage. Correspondingly, $\mathrm{PGCl} \alpha$ might play an opposite role. As previously reported, muscles from the TB mice had a higher level of phosphorylated C/EBP $\beta$, along with a modest increase in total C/EBP $\beta$, on day 14 for the LLC model $(10,44)$. In our opinion, the LLC model TB mice sacrificed on day 14 were the ECC mice in this study. However, we measured the protein levels of total $\mathrm{C} / \mathrm{EBP} \beta$ in the muscles from the ECC mice of both models and found that they were not significantly different. This result is consistent with the previous report. In addition, we showed that the protein expression of HDAC1 was increased in muscles from the LCC mice of both models. The change in HDAC 3 expression was similar to that in HDAC1 expression. In contrast, HDAC3 has been reported to be decreased in dexamethasoneinduced muscle wasting (47). Although this finding is not consistent with our data, it suggests that HDAC 3 is indeed involved in muscle wasting and might have different roles in different models. The role of PGC1 $\alpha$ in protecting muscles from wasting has been proven $(35,40)$. In our experiment, this role might be inhibited in both the C26 and LLC models.

miR-30c may play a role in LCC mice. Many studies have verified that the levels of microRNAs are altered in muscles from cancer cachectic mice. We used different miRNA targetpredicting algorithms (for example, TargetScan and RegRNA) to identify potential miRNAs that could affect the aforementioned genes. We found conserved miR-30c sites in the 3'UTRs of atrogin1, FoxO3a and HDAC3 (Fig. 9A). Moreover, we found a conserved miR-30c site in the 5'UTR of PGC1 $\alpha$ (Fig. 9A). Consequently, we observed that the miR-30c level was not altered in muscles from the ECC mice of the $\mathrm{C} 26$ model but that it was decreased in the LCC mice of both models (Fig. 9B and C). Our observations indicate that miR-30c might be involved in the process of cancer cachexia by interfering with the expression of PGC1 $\alpha$, atrogin1, FoxO3a and HDAC3. Further research needs to be performed to determine whether these genes are directly regulated by miR-30c.

Molecules with no change in ECC do not necessarily indicate no effect on muscle wasting. By comparing the changes in the expression of crucial molecules involved in muscle wasting in both the ECC and LCC mice, we confirmed that some molecules exhibited varying degrees of change in our models. Although the expression levels of several other molecules did not obviously change in the ECC mice, they were significantly altered in the LCC mice, such as PGCl $\alpha, \mathrm{C} / \mathrm{EBP} \beta$ and HDACs. However, it is still difficult to conclude that these unchanged molecules do not play roles in the ECC mice. For instance, the role of HDACs in muscle wasting has been realized in recent years, and pharmacological interventions with HDAC inhibitors have been shown to increase myofiber size and counter the functional decline of dystrophic muscles (55). In addition, class II HDACs promote neurogenic muscle atrophy by inducing E3 ubiquitin ligases (56). These findings suggest that HDACs might accelerate the process of muscle wasting induced by cancer. A previous report has shown that the total protein level of HDAC1 does not change in disused muscle but that the relative abundance of HDAC1 is decreased in the nuclear fraction and increased in the cytosol (49). These data suggest that HDAC1 may shuttle out of the nucleus to exert its function within the cytoplasm. In our models, the protein level of HDAC1 was increased in the LCC mice, but not in the ECC mice. This finding does not indicate that HDAC1 plays no role in muscle wasting in ECC mice. The function of this molecule might have been further enhanced when its level was increased in the LCC mice.

In conclusion, our results have revealed that the expression levels of several molecules are altered in muscles from LCC mice, but not in those from ECC mice. From our results we deduce that these changes may promote muscle wasting in late cancer cachexia. The data in this study may facilitate the further understanding of the underlying mechanism involved in the development of cancer cachexia. However, our present study on muscle wasting in late cancer cachexia merely sheds light on the underlying mechanism, which remains poorly understood. Thus, further investigation is warranted to delineate the foundation of late cancer cachexia to provide a solid basis for the clinical prediction and prevention of muscle wasting in cancer cachexia.

\section{Acknowledgements}

The present study was supported by the National Natural Science Foundation of China (NSFC; grant no. 81272560), the Open Research Foundation of the State Key Laboratory 
of Virology of Wuhan University (grant no. 2014KF007), the Hubei Province Scientific and Technical Project (grant no. 2011CDB366), and the Hubei Provincial Health Project (grant no. WJ2015MB020) to H.Y. The study was also supported by the National Natural Science Foundation of China (grant nos. 30872924, 81072095 and 81372760), the Program for New Century Excellent Talents in University from the Department of Education of China (NCET-08-0223), and the National High Technology Research and Development Program of China (863 Program) (2012AA021101) to X.Z.

\section{References}

1. Argilés JM, Busquets S, Stemmler B and López-Soriano FJ: Cancer cachexia: Understanding the molecular basis. Nat Rev Cancer 14: 754-762, 2014.

2. Li B, Wan L, Li Y, Yu Q, Chen P, Gan R, Yang Q, Han Y and Guo C: Baicalin, a component of Scutellaria baicalensis, alleviates anorexia and inhibits skeletal muscle atrophy in experimental cancer cachexia. Tumour Biol 35: 12415-12425, 2014.

3. Talbert EE, Metzger GA, He WA and Guttridge DC: Modeling human cancer cachexia in colon 26 tumor-bearing adult mice. J Cachexia Sarcopenia Muscle 5: 321-328, 2014.

4. Cai D, Frantz JD, Tawa NE Jr, Melendez PA, Oh BC, Lidov HG, Hasselgren PO, Frontera WR, Lee J, Glass DJ, et al: IKKbeta/ NF-kappaB activation causes severe muscle wasting in mice. Cell 119: 285-298, 2004.

5. Acharyya S, Ladner KJ, Nelsen LL, Damrauer J, Reiser PJ, Swoap S and Guttridge DC: Cancer cachexia is regulated by selective targeting of skeletal muscle gene products. J Clin Invest 114: 370-378, 2004.

6. Bonetto A, Aydogdu T, Jin X, Zhang Z, Zhan R, Puzis L, Koniaris LG and Zimmers TA: JAK/STAT3 pathway inhibition blocks skeletal muscle wasting downstream of IL- 6 and in experimental cancer cachexia. Am J Physiol Endocrinol Metab 303: E410-E421, 2012.

7. Ham DJ, Murphy KT, Chee A, Lynch GS and Koopman R: Glycine administration attenuates skeletal muscle wasting in a mouse model of cancer cachexia. Clin Nutr 33: 448-458, 2014.

8. Bonetto A, Aydogdu T, Kunzevitzky N, Guttridge DC, Khuri S, Koniaris LG and Zimmers TA: STAT3 activation in skeletal muscle links muscle wasting and the acute phase response in cancer cachexia. PLoS One 6: e22538, 2011.

9. Murphy KT, Chee A, Trieu J, Naim T and Lynch GS: Importance of functional and metabolic impairments in the characterization of the C-26 murine model of cancer cachexia. Dis Model Mech 5: 533-545, 2012.

10. Zhang G, Jin B and Li YP: C/EBP $\beta$ mediates tumour-induced ubiquitin ligase atrogin $1 / \mathrm{MAFbx}$ upregulation and muscle wasting. EMBO J 30: 4323-4335, 2011.

11. Busquets S, Toledo M, Orpí M, Massa D, Porta M, Capdevila E, Padilla N, Frailis V, López-Soriano FJ, Han HQ, et al: Myostatin blockage using actRIIB antagonism in mice bearing the Lewis lung carcinoma results in the improvement of muscle wasting and physical performance. J Cachexia Sarcopenia Muscle 3: 37-43, 2012.

12. Ruas JL, White JP, Rao RR, Kleiner S, Brannan KT, Harrison BC, Greene NP, Wu J, Estall JL, Irving BA, et al: A PGC-1 $\alpha$ isoform induced by resistance training regulates skeletal muscle hypertrophy. Cell 151: 1319-1331, 2012.

13. Reed SA, Sandesara PB, Senf SM and Judge AR: Inhibition of FoxO transcriptional activity prevents muscle fiber atrophy during cachexia and induces hypertrophy. FASEB J 26: 987-1000, 2012.

14. Puppa MJ, Gao S, Narsale AA and Carson JA: Skeletal muscle glycoprotein 130's role in Lewis lung carcinoma-induced cachexia. FASEB J 28: 998-1009, 2014.

15. He SS, Wu QJ, Gong CY, Luo ST, Zhang S, Li M, Lu L, Wei YQ and Yang L: Enhanced efficacy of combination therapy with adeno-associated virus-delivered pigment epithelium-derived factor and cisplatin in a mouse model of Lewis lung carcinoma. Mol Med Rep 9: 2069-2076, 2014.

16. Wang H, Lai YJ, Chan YL, Li TL and Wu CJ: Epigallocatechin3 -gallate effectively attenuates skeletal muscle atrophy caused by cancer cachexia. Cancer Lett 305: 40-49, 2011.
17. Fearon KC, Glass DJ and Guttridge DC: Cancer cachexia: Mediators, signaling, and metabolic pathways. Cell Metab 16: 153-166, 2012.

18. Johns N, Stephens NA and Fearon KC: Muscle wasting in cancer. Int J Biochem Cell Biol 45: 2215-2229, 2013.

19. McPherron AC, Lawler AM and Lee SJ: Regulation of skeletal muscle mass in mice by a new TGF-beta superfamily member. Nature 387: 83-90, 1997.

20. Padrão AI, Oliveira P, Vitorino R, Colaço B, Pires MJ, Márquez M, Castellanos E, Neuparth MJ, Teixeira C, Costa C, et al: Bladder cancer-induced skeletal muscle wasting: Disclosing the role of mitochondria plasticity. Int J Biochem Cell Biol 45: 1399-1409, 2013

21. Padrão AI, Moreira-Gonçalves D, Oliveira PA, Teixeira C, Faustino-Rocha AI, Helguero L, Vitorino R, Santos LL, Amado F, Duarte JA, et al: Endurance training prevents TWEAK but not myostatin-mediated cardiac remodelling in cancer cachexia. Arch Biochem Biophys 567: 13-21, 2015.

22. Gallot YS, Durieux AC, Castells J, Desgeorges MM, Vernus B, Plantureux L, Rémond D, Jahnke VE, Lefai E, Dardevet D, et al: Myostatin gene inactivation prevents skeletal muscle wasting in cancer. Cancer Res 74: 7344-7356, 2014.

23. Han HQ, Zhou X, Mitch WE and Goldberg AL: Myostatin/ activin pathway antagonism: Molecular basis and therapeutic potential. Int J Biochem Cell Biol 45: 2333-2347, 2013.

24. Zhou X, Wang JL, Lu J, Song Y, Kwak KS, Jiao Q, Rosenfeld R, Chen Q, Boone T, Simonet WS, et al: Reversal of cancer cachexia and muscle wasting by ActRIIB antagonism leads to prolonged survival. Cell 142: 531-543, 2010.

25. Lokireddy S, Wijesoma IW, Bonala S, Wei M, Sze SK, McFarlane C, Kambadur R and Sharma M: Myostatin is a novel tumoral factor that induces cancer cachexia. Biochem J 446: 23-36, 2012.

26. Ramaswamy S, Nakamura N, Sansal I, Bergeron L and Sellers WR: A novel mechanism of gene regulation and tumor suppression by the transcription factor FKHR. Cancer Cell 2: 81-91, 2002.

27. Sandri M, Sandri C, Gilbert A, Skurk C, Calabria E, Picard A, Walsh K, Schiaffino S, Lecker SH and Goldberg AL: Foxo transcription factors induce the atrophy-related ubiquitin ligase atrogin-1 and cause skeletal muscle atrophy. Cell 117: 399-412, 2004.

28. Bodine SC, Latres E, Baumhueter S, Lai VK, Nunez L, Clarke BA, Poueymirou WT, Panaro FJ, Na E, Dharmarajan K, et al: Identification of ubiquitin ligases required for skeletal muscle atrophy. Science 294: 1704-1708, 2001.

29. Gomes MD, Lecker SH, Jagoe RT, Navon A and Goldberg AL: Atrogin-1, a muscle-specific F-box protein highly expressed during muscle atrophy. Proc Natl Acad Sci USA 98: 14440-14445, 2001.

30. Cohen S, Nathan JA and Goldberg AL: Muscle wasting in disease: Molecular mechanisms and promising therapies. Nat Rev Drug Discov 14: 58-74, 2015.

31. Wang DT, Yang YJ, Huang RH, Zhang ZH and Lin X: Myostatin activates the ubiquitin-proteasome and autophagy-lysosome systems contributing to muscle wasting in chronic kidney disease. Oxid Med Cell Longev 2015: 684965, 2015.

32. Attaix D, Ventadour S, Codran A, Béchet D, Taillandier D and Combaret L: The ubiquitin-proteasome system and skeletal muscle wasting. Essays Biochem 41: 173-186, 2005.

33. Taillandier D, Combaret L, Pouch MN, Samuels SE, Béchet D and Attaix D: The role of ubiquitin-proteasome-dependent proteolysis in the remodelling of skeletal muscle. Proc Nutr Soc 63: 357-361, 2004

34. Lokireddy S, Wijesoma IW, Sze SK, McFarlane C, Kambadur R and Sharma M: Identification of atrogin-1-targeted proteins during the myostatin-induced skeletal muscle wasting. Am J Physiol Cell Physiol 303: C512-C529, 2012.

35. Sandri M, Lin J, Handschin C, Yang W, Arany ZP, Lecker SH, Goldberg AL and Spiegelman BM: PGC-1alpha protects skeletal muscle from atrophy by suppressing FoxO3 action and atrophyspecific gene transcription. Proc Natl Acad Sci USA 103: 16260-16265, 2006.

36. Esterbauer H, Oberkofler H, Krempler F and Patsch W: Human peroxisome proliferator activated receptor gamma coactivator 1 (PPARGC1) gene: cDNA sequence, genomic organization, chromosomal localization, and tissue expression. Genomics 62: 98-102, 1999

37. Puigserver P: Tissue-specific regulation of metabolic pathways through the transcriptional coactivator PGC1-alpha. Int J Obes 29 (Suppl 1): S5-S9, 2005. 
38. Brault JJ, Jespersen JG and Goldberg AL: Peroxisome proliferator-activated receptor gamma coactivator 1alpha or 1beta overexpression inhibits muscle protein degradation, induction of ubiquitin ligases, and disuse atrophy. J Biol Chem 285: 19460-19471, 2010.

39. Cannavino J, Brocca L, Sandri M, Bottinelli R and Pellegrino MA PGC1- $\alpha$ over-expression prevents metabolic alterations and soleus muscle atrophy in hindlimb unloaded mice. J Physiol 592: $4575-4589,2014$

40. Wenz T, Rossi SG, Rotundo RL, Spiegelman BM and Moraes CT: Increased muscle PGC-1alpha expression protects from sarcopenia and metabolic disease during aging. Proc Natl Acad Sci USA 106: 20405-20410, 2009.

41. Ramji DP and Foka P: CCAAT/enhancer-binding proteins: Structure, function and regulation. Biochem J 365: 561-575, 2002.

42. Allen DL, Bandstra ER, Harrison BC, Thorng S, Stodieck LS, Kostenuik PJ, Morony S, Lacey DL, Hammond TG, Leinwand LL, et al: Effects of spaceflight on murine skeletal muscle gene expression. J Appl Physiol (1985) 106: 582-595, 2009.

43. Penner G, Gang G, Sun X, Wray C and Hasselgren PO: C/ EBP DNA-binding activity is upregulated by a glucocorticoiddependent mechanism in septic muscle. Am J Physiol Regul Integr Comp Physiol 282: R439-R444, 2002.

44. Zhang G and Li YP: p38 $\beta$ MAPK upregulates atrogin1/MAFbx by specific phosphorylation of C/EBP $\beta$. Skelet Muscle 2: 20, 2012.

45. McKinsey TA, Zhang CL and Olson EN: Control of muscle development by dueling HATs and HDACs. Curr Opin Genet Dev 11: 497-504, 2001.

46. Alamdari N, Aversa Z, Castillero E and Hasselgren PO: Acetylation and deacetylation - novel factors in muscle wasting. Metabolism 62: 1-11, 2013.

47. Yang H, Wei W, Menconi M and Hasselgren PO: Dexamethasoneinduced protein degradation in cultured myotubes is $\mathrm{p} 300 /$ HAT dependent. Am J Physiol Regul Integr Comp Physiol 292 . R337-R334, 2007.
48. Demos-Davies KM, Ferguson BS, Cavasin MA, Mahaffey JH, Williams SM, Spiltoir JI, Schuetze KB, Horn TR, Chen B, Ferrara C, et al: HDAC6 contributes to pathological responses of heart and skeletal muscle to chronic angiotensin-II signaling. Am J Physiol Heart Circ Physiol 307: H252-H258, 2014.

49. Beharry AW, Sandesara PB, Roberts BM, Ferreira LF, Senf SM and Judge AR: HDAC1 activates FoxO and is both sufficient and required for skeletal muscle atrophy. J Cell Sci 127: 1441-1453, 2014.

50. Greco S, De Simone M, Colussi C, Zaccagnini G, Fasanaro P, Pescatori M, Cardani R, Perbellini R, Isaia E, Sale P, et al: Common micro-RNA signature in skeletal muscle damage and regeneration induced by Duchenne muscular dystrophy and acute ischemia. FASEB J 23: 3335-3346, 2009.

51. Guess MG, Barthel KK, Harrison BC and Leinwand LA: miR-30 family microRNAs regulate myogenic differentiation and provide negative feedback on the microRNA pathway. PLoS One 10: e0118229, 2015

52. Cavallo F, Calogero RA and Forni G: Are oncoantigens suitable targets for anti-tumour therapy? Nat Rev Cancer 7: 707-713, 2007.

53. Das SK, Eder S, Schauer S, Diwoky C, Temmel H, Guertl B, Gorkiewicz G, Tamilarasan KP, Kumari P, Trauner M, et al: Adipose triglyceride lipase contributes to cancer-associated cachexia. Science 333: 233-238, 2011.

54. Kliewer KL, Ke JY, Tian M, Cole RM, Andridge RR and Belury MA: Adipose tissue lipolysis and energy metabolism in early cancer cachexia in mice. Cancer Biol Ther: 0, 2014.

55. Minetti GC, Colussi C, Adami R, Serra C, Mozzetta C, Parente V, Fortuni S, Straino S, Sampaolesi M, Di Padova M, et al: Functional and morphological recovery of dystrophic muscles in mice treated with deacetylase inhibitors. Nat Med 12: $1147-1150,2006$

56. Moresi V, Williams AH, Meadows E, Flynn JM, Potthoff MJ, McAnally J, Shelton JM, Backs J, Klein WH, Richardson JA, et al: Myogenin and class II HDACs control neurogenic muscle atrophy by inducing E3 ubiquitin ligases. Cell 143: 35-45, 2010. 